\title{
Análise dos instrumentos prudenciais, disciplinares e punitivos aplicados pelo Banco Central do Brasil no período de 2008 a 2017
}

\author{
Carolina Just Bacha* \\ Helberte João França Almeida**
}

\section{Resumo}

O sistema financeiro possui um papel relevante para o desenvolvimento de um país, ao desempenhar a função de intermediação financeira, o sistema de pagamentos da economia e a oferta de ativos para diferentes perfis de risco. A alavancagem aliada às diferentes maturidades entre ativos e passivos aumentam os riscos do sistema financeiro. Dentre esses está o sistêmico, no qual a quebra de um banco pode causar externalidades negativas sobre instituições semelhantes e a perda de confiança dos agentes. Para evitar, o Banco Central atua na regulação do Sistema Financeiro Nacional, utilizando instrumentos disciplinares e punitivos contra instituições que descumprem suas recomendações. Logo, este trabalho analisa os históricos das penalidades aplicadas e das decisões proferidas, as instituições mais punidas e os tipos de processos que mais ensejaram a aplicação de multas e o seu valor, de 2008 a 2017. Observou-se que as cooperativas foram as instituições que mais receberam advertências e inabilitações e que as multas tiveram, nos últimos anos, aplicação crescente, sendo as pessoas físicas as mais penalizadas.

Palavras-chave: sistema financeiro nacional; instrumentos; regulação.

\section{Analysis of the prudential, disciplinary and punitive instruments applied by the Central Bank of Brasil from 2008 to 2017}

\begin{abstract}
The financial system has a relevant role for the development of a country, by playing the role of financial intermediation, the payment system of the economy and the supply of assets for different risk profiles. Leverage combined with different maturities between assets and liabilities increase the risks of the financial system. Among these is the systemic, in which the bankruptcy of a bank can cause negative externalities and loss of confidence of the agents. To avoid, the Central Bank acts in the regulation of the National Financial System, using disciplinary and punitive instruments to be used against institutions that fail to comply with its recommendations. Therefore, the paper analyze the history of the penalties applied and the decisions handed down, the most punished institutions and the types of processes that gave rise to the application of fines and their value from 2008 to 2017. It was observed that the cooperatives were the institutions who received more warnings and disqualifications and that the fines had, in recent years, an increase in application, with individuals being the most penalized.
\end{abstract}

Keywords: national financial system; prudential, instruments; regulation.

JEL: E58; G2; G28

\footnotetext{
* Mestranda em Direito no Programa de Pós-Graduação em Direito (PPGD) da Universidade Federal de Santa Catarina, UFSC. E-mail: carol_bacha@hotmail.com

** Professor Dr. Departamento de Economia e Relações Internacionais, Universidade Federal de Santa Catarina, UFSC.E-mail: helberte.almeida@ufsc.br
} 


\section{INTRODUÇÃO}

O sistema financeiro de um país é caracterizado por um conjunto de instituições que facilitam a transferência de recursos disponíveis dos agentes superavitários para os agentes deficitários, porquanto possibilitam o "casamento" das pretensões dos mesmos. Além disso, a intermediação financeira mostra-se importante na redução dos custos de transação, na medida em que, operando em economias de escala, as instituições financeiras conseguem diminuir os custos de aquisição de informações e seu monitoramento.

De acordo com Carvalho (2010), em uma economia monetária de produção, o sistema financeiro tem um papel relevante no apoio ao desenvolvimento econômico de um país. Isso ocorre em razão de três funções, a saber: a) disponibilizar recursos financeiros que serão utilizados no processo produtivo e na realização de investimentos capazes de ampliar e modernizar a capacidade produtiva existente na economia; b) criar ativos para diferentes perfis de agentes privados, para que os mesmos acumulem riquezas; e, c) realizar o sistema de pagamentos na economia brasileira.

Conjuntamente a estas funções, o setor financeiro apresenta um risco que é inerente deste setor, o risco sistêmico. Este está relacionado com a possibilidade de que a falência de uma determinada instituição financeira, especialmente de bancos, reflita em externalidades negativas às demais instituições semelhantes que atuam no setor, podendo levar toda uma economia ao colapso. Assim, diferentemente do que ocorre com outras empresas industriais, no setor financeiro a quebra de um banco provoca o fenômeno do "contágio", porque os depositantes acabam perdendo a confiança no mercado financeiro, mesmo que as instituições afetadas estejam operando em observância às regulamentações (CARVALHO, 2005).

De acordo com Carvalho (2005), os depósitos à vista e moeda legal são considerados substitutos perfeitos, desde que haja a confiança do público de que o banco honrará seu compromisso de pagamento. Todavia, os bancos não podem garantir o risco de crédito nulo, pois operam de forma alavancada, ou seja, emprestam além daquilo que detém de reservas em moeda legal. Ademais, deve-se levar em conta que os bancos operam com passivos e ativos em maturidades diferentes, uma vez que os depósitos (passivos) podem ser exigidos no curto prazo, enquanto os empréstimos concedidos pelos bancos (ativos) serão pagos apenas em um tempo futuro. Assim, caso ocorra desconfiança por parte dos depositantes acerca da capacidade do banco de honrar os contratos, poderão ocorrer às chamadas corridas bancárias (CARVALHO, 2007). 
Importante destacar que a existência de assimetrias de informação - seleção adversa e risco moral - no sistema financeiro, também impõe a criação de regulações que protegerão os consumidores e garantirão maior eficiência do mercado (CARVALHO, 2007). Desta maneira, o presente trabalho analisará os tipos de regulação, bem como os mecanismos existentes para a consecução das mesmas. Ademais, serão verificados quais são os instrumentos prudenciais, disciplinares e punitivos que o Banco Central pode se valer para fazer com que as instituições financeiras que atuam em desacordo com as recomendações legais, inibam o seu comportamento e diminuam os elevados riscos, minimizando assim, as possibilidades de crise.

A contribuição deste estudo na literatura de regulação prudencial é avaliar as penalidades, advertências, inabilitações e multas aplicadas pelo Banco Central as instituições financeiras no período de 2008 a 2017. Além disto, também se verifica em que medida estas infrações podem ser explicadas por mudanças nas leis e regulações ou até mesmo fruto de uma maior investigação criminal.

Além desta introdução, o trabalho encontra-se estruturado da seguinte maneira. A seção dois apresenta o referencial teórico, focando nos fatores que influenciam as regulamentações sistêmica, prudencial e o processo administrativo sancionador. Posteriormente, a seção três expõe e discute os resultados encontrados. Por fim, a seção quatro traz as considerações finais.

\section{REGULAÇÃO SISTÊMICA E REGULAÇÃO PRUDENCIAL}

No Brasil, o órgão responsável pela regulação, monitoramento e supervisão do Sistema Financeiro Nacional é o Banco Central, o qual tem à sua disposição mecanismos que podem ser utilizados nas regulações de conduta, sistêmica e prudencial. O primeiro tipo de regulação refere-se à adoção de regras e regimes prescritivos que autorizam ou proíbem determinadas práticas, ou delimitam operações e estruturas de mercado, englobando desde regramentos quanto à oferta dos produtos financeiros até a obrigação de prestar informações. Por seu turno, a regulação sistêmica abrange a criação de "redes de proteção ${ }^{1 "}$ ", por meio de instrumentos que permitam a administração das crises ou inibam a difusão das mesmas. Por

\footnotetext{
${ }^{1}$ Redes de proteção é definido como os instrumentos e mecanismos utilizados pelo Banco Central do Brasil com a finalidade de proteger o Sistema Financeiro Nacional e garantir a manutenção de sua estabilidade (CARVALHO, 2007).
} 
fim, a regulação prudencial é vista como uma medida preventiva das crises sistêmicas (YAZBEK, 2007).

Dentre os instrumentos utilizados na regulação sistêmica estão os regimes excepcionais de intervenção, liquidação extrajudicial e administração especial temporária, sendo os primeiros disciplinados pela Lei n. 6.024/74 e o último pelo Decreto-Lei $n$. 2.321/87. Desta forma, verificadas anormalidades nos negócios das instituições financeiras poderá o Bacen decretar a intervenção (a qual suspende a exigibilidade das obrigações vencidas e a fluência dos prazos das vincendas) ou a administração especial temporária (a qual não interrompe, nem suspende as atividades da entidade). Por fim, quando verificados motivos que autorizem a declaração de falência da instituição, o Bacen poderá proceder a sua liquidação extrajudicial, medida considerada mais gravosa, tendo em vista tratar-se da extinção da instituição.

Outros instrumentos de regulação sistêmica são os fundos e seguros garantidores de depósito, mecanismos que elevam a confiança dos depositantes e evitam as corridas bancárias. O Fundo Garantidor de Crédito (FGC) é regulamentado pela Resolução n. 4.222/13 do Banco Central, sendo atualmente o responsável pela proteção dos depositantes a nível nacional. Atualmente, o FGC garante até o montante máximo de R $\$ 250.000,00$ (duzentos e cinquenta mil reais) por pessoa contra a mesma instituição financeira ou instituições do mesmo conglomerado financeiro.

Além dos regimes excepcionais e dos fundos garantidores de crédito, as instituições solventes, mas com problemas de liquidez de curto prazo, podem contar com a ajuda do Banco Central como emprestador de última instância. Essa prática, contudo, pode ocasionar o risco moral naquelas instituições que, sabendo que serão protegidas, poderão incorrer em riscos bastante elevados, operando com um nível de reservas muito abaixo do ideal. Essa anomalia pode ser resolvida com a cobrança de taxas punitivas na concessão do empréstimo e mediante apresentação de bons colaterais por parte das instituições tomadoras. Porém, Carvalho (2005, p. 43) destaca que "o emprestador entra em cena quando o mercado bancário já está sob tensão, quando as fontes de financiamento normais com que conta um banco (por exemplo, o mercado interbancário de reservas) já se fechou para a instituição que busca apoio". Deste modo, os empréstimos concedidos pelo Banco Central configuram-se uma última alternativa para evitar que aqueles bancos que estão tendo problemas de liquidez, possam colocar em risco a estabilidade do sistema financeiro. Referidos instrumentos, portanto, são essenciais para evitar as corridas bancárias, tendo em vista a manutenção da 
confiança dos depositantes, em razão da existência de instituições que garantirão os seus recursos (CARVALHO, 2005).

Por sua vez, na regulação prudencial, o Banco Central atua preventivamente à ocorrência de crises. Para tanto, qualquer instituição financeira, para poder exercer as suas atividades, precisa ter autorização de funcionamento concedida pelo Bacen. Outrossim, durante o exercício das suas atividades, as entidades supervisionadas precisam controlar seus riscos, a fim de não operarem de forma muito alavancada, adequando, ainda, o seu nível de capital em relação aos riscos. Essa adequação se mostra essencial para que as instituições obtenham uma margem de segurança para situações inesperadas, e para que não incorram em riscos excessivos que possam causar um colapso no sistema como um todo (MISHKIN, 2001). Deste modo, as instituições financeiras precisam enviar informações ao órgão central, para que o mesmo avalie se o grau de risco por elas assumido está dentro dos limites regulamentares, bem como se as normas legais estão sendo respeitadas. Destaca-se que os coeficientes de capitais mínimos impostos aos bancos foram, dentre outras exigências, estabelecidos pelos Acordos de Basileia $^{2}$ que representaram avanços, cada qual em sua época, para a regulação prudencial.

Observa-se que o Banco Central dispõe, ainda, de instrumentos prudenciais, disciplinares e punitivos, os quais podem ser aplicados em desfavor das instituições que descumpram as normas legais e exponham o Sistema Financeiro Nacional a risco. Existem medidas, como as prudenciais preventivas e cautelares, bem como as exigências de apresentação de plano de regularização que podem ser utilizadas pelo Bacen para fazer com que as instituições supervisionadas se adequem às recomendações e normas legais.

\subsection{PROCESSO ADMINISTRATIVO SANCIONADOR}

O Banco Central do Brasil, no exercício de sua função fiscalizadora, caso verifique que as instituições supervisionadas cometeram atos ilícitos, poderá instaurar processo

\footnotetext{
${ }^{2}$ Em 1930, foi criado o Banco de Compensações Internacional (BIS) que tinha como objetivo uma maior cooperação entre os Bancos Centrais. Em 1975, após verificada a necessidade de maior coordenação e padronização das regras bancárias à nível internacional foi criado o Comitê da Basileia, que realizou seu primeiro acordo no ano de 1988. Esse acordo previa a exigência de capital mínimo, ponderado pelo risco para as instituições financeiras. Diante das mudanças decorrentes da maior integração entre as instituições financeiras, em 2004, verificou-se a necessidades de reformas do acordo antes estabelecido, a essa revisão foi dado o nome de Basileia II. Atualmente está em vigor o Basileia III que buscou aprimorar a regulação prudencial, enfatizando a prevenção às instabilidades no setor financeiro (BACEN, 2018a).
} 
administrativo sancionador, o qual é regido pela Lei n. 13.506/2017 e aplicar as penalidades cabíveis.

Estão sujeitas à aplicação de tais penas as seguintes instituições, a saber: bancos múltiplos, comerciais e caixas econômicas; bancos de investimento, de desenvolvimento e de câmbio; agências de fomento; financeiras; corretoras e distribuidoras; sociedades de arrendamento mercantil; sociedades de crédito imobiliário; associações de poupança e empréstimo; companhias hipotecárias; cooperativas de crédito; sociedades de crédito ao microempreendedor; administradoras de consórcios; administradores e membros de comitês estatutários de instituições financeiras; empresas de auditoria e auditores independentes; auditores responsáveis pela auditoria de instituições financeiras e demais instituições autorizadas a funcionar pelo Bacen; entidades de auditoria cooperativa; operadoras de sistemas de compensação e liquidação; pessoas físicas e jurídicas que infrinjam as normas cambiais e relativas ao fluxo de capitais internacionais, bem como aquelas que atuem em atividades supervisionadas pelo Banco Central, mas sem a sua autorização (BACEN, 2018b).

As infrações que ensejam a aplicação de punições estão previstas no art. $3^{\circ}$ da Lei n. 13.506/17, dentre elas: realizar operações no SFN em desacordo com os princípios e normas que regem a atividade financeira ou não autorizadas pelo Bacen; obstar ou dificultar a fiscalização; não enviar dados e informações exigidos pelo Banco Central ou apresentá-los com informações incorretas ou fora dos prazos estabelecidos; atuar como administrador sem a autorização do Bacen; realizar operações de crédito ou arrendamento mercantil em preços destoantes ao do mercado; simular operações para obter vantagens indevidas; desviar recursos de terceiros ou da própria instituição financeira; inserir ou manter informações falsas ou incorretas nas demonstrações contábeis ou em relatórios de auditoria; remunerar acionistas, administradores e outros membros com base em resultados apurados por demonstrações contábeis falsas ou incorretas; deixar de agir com prudência e diligência na condução dos interesses da instituição financeira; confundir o patrimônio da entidade financeira com o de outras sociedades; descumprir as determinações do Bacen e, de modo geral, as normas legais e regulamentares do SFN (BRASIL, 2017).

Constatada alguma das infrações descritas ou, ainda, qualquer irregularidade que exponha o SFN a risco, poderá o Bacen, após a instauração do processo administrativo sancionador, aplicar as penalidades cabíveis de acordo com cada caso concreto, em observância à gravidade e duração da infração, o grau de lesão ou perigo provocado ao SFN, 
o valor da operação, a vantagem obtida pelo infrator, bem como a sua colaboração para a apuração dos fatos (BRASIL, 2017).

A Lei n. 13.506/17 prevê em seu art. $5^{\circ}$ as penas de admoestação pública ${ }^{3}$, multa, proibição para atuar, inabilitação e cessação da autorização de funcionamento, as quais podem ser aplicadas isolada ou cumulativamente. Além das penalidades descritas, a Lei n. 9.613/98 (Lei da Lavagem de Dinheiro) também estabelece a advertência como pena aplicável contra os infratores. Observa-se que o Banco Central tem competência para aplicar punições aos transgressores das obrigações constantes na Lei n. 9.613/98 (BACEN, 2018b).

A seguir são apresentados os históricos das penalidades mais utilizadas pelo Banco Central, sendo possível observar quais as penas mais utilizadas pela autarquia e contra quais instituições estas punições são mais aplicadas. Da mesma forma, são analisados o número de decisões proferidas, os tipos de processo (cambial, financeiro ou de fluxo de capitais) que mais ensejaram a aplicação das penas, bem como o valor das multas impostas. Portanto, é possível verificar se existe alguma tendência de queda ou ascensão da aplicação das infrações no período de 2008 a 2017.

\section{HISTÓRICO DE PENALIDADES APLICADAS}

Esta seção tem por objetivo apresentar o histórico de penalidades impostas em cada ano. Assim, consultando os dados do Banco Central do Brasil, referentes às penalidades impostas em cada ano, são possíveis verificar que as infrações mais aplicadas foram: advertências, inabilitações ${ }^{4}$, multas e proibições para atuar ${ }^{5}$.

\footnotetext{
${ }^{3} \mathrm{~A}$ admoestação pública refere-se à publicação de um texto em que conste o nome do infrator, a conduta ilícita e a sanção imposta no site da autarquia que aplicou a penalidade, de acordo com o art. $6^{\circ}, \S \S 1^{\circ}$ e $2^{\circ}$ da Lei $n$. $13.506 / 17$.

${ }^{4}$ Inabilitação, por até 20 anos, para atuar como administrador e para exercer cargos em órgãos previstos no contrato social ou estatuto das instituições financeiras autorizadas pelo Bacen a funcionar.

${ }^{5}$ Proibição, por até 20 anos, de praticar atividades ou prestar serviços a instituições autorizadas pelo Bacen a funcionar.
} 
Tabela 1 - Penalidades aplicadas em 1ª instância no período de 2008 a 2017

Penalidades aplicadas em 1a instância no período de 2008 a 2017

\begin{tabular}{|lrrrrrrrrrr|r|r|}
\hline $\begin{array}{l}\text { Por tipo de penalidade } \\
\text { Penalidade }\end{array}$ & $\mathbf{2 0 0 8}$ & $\mathbf{2 0 0 9}$ & $\mathbf{2 0 1 0}$ & $\mathbf{2 0 1 1}$ & $\mathbf{2 0 1 2}$ & $\mathbf{2 0 1 3}$ & $\mathbf{2 0 1 4}$ & $\mathbf{2 0 1 5}$ & $\mathbf{2 0 1 6}$ & $\mathbf{2 0 1 7}$ & Total \\
\hline ADVERTÊNCIA & 8 & 10 & 16 & 27 & 38 & 21 & 20 & 12 & 21 & 4 & 177 \\
\hline INABILTTAÇÃO & 205 & 115 & 129 & 293 & 470 & 198 & 316 & 152 & 160 & 5 & 2043 \\
\hline MULTA & 1544 & 712 & 779 & 272 & 296 & 558 & 781 & 1129 & 1232 & 2364 & 9667 \\
\hline PROIBIÇÃO PARA ATUAR & 4 & 1 & 0 & 1 & 2 & 3 & 11 & 1 & 0 & 0 & 23 \\
\hline & Total & $\mathbf{1 7 6 1}$ & $\mathbf{8 3 8}$ & $\mathbf{9 2 4}$ & $\mathbf{5 9 3}$ & $\mathbf{8 0 6}$ & $\mathbf{7 8 0}$ & $\mathbf{1 1 2 8}$ & $\mathbf{1 2 9 4}$ & $\mathbf{1 4 1 3}$ & $\mathbf{2 3 7 3}$ & $\mathbf{1 1 9 1 0}$ \\
\hline
\end{tabular}

Fonte: Bacen, 2018.

É possível verificar, de acordo com a Tabela 1, que as penas de multa foram as mais utilizadas pelo Banco Central, desta maneira, de 2008 até 2017 observou-se a ocorrência de 9.667 multas, sendo que o ano de 2017 foi o que apresentou a maior quantidade aplicada durante o período de estudo, no total de 2.364 .

As inabilitações são as segundas penalidades mais utilizadas, as quais totalizaram 2.043, sendo constatada em 2012 a sua maior ocorrência, com 470 inabilitações só naquele ano. Seguidas das inabilitações, verifica-se a imposição de 177 advertências no período, sendo também em 2012 o ano com maior aplicação das mesmas. Em 2017 pode ser observada uma redução tanto da quantidade de advertências, quanto de inabilitações. Por sua vez, a proibição para atuar foi a penalidade menos utilizada, sendo constatadas apenas 23 ocorrências no período de mais de dez anos.

Do total de penalidades aplicadas, constata-se que o ano de 2017, seguido do ano de 2008 , foram os que obtiveram mais penas impostas. O Gráfico 1 apresenta a quantidade de decisões proferidas no intervalo em estudo. 
Gráfico 1 - Total de decisões proferidas (2008 a 2017)

\section{TOTAL DE DECISÕES PROFERIDAS (2008 - 2017)}

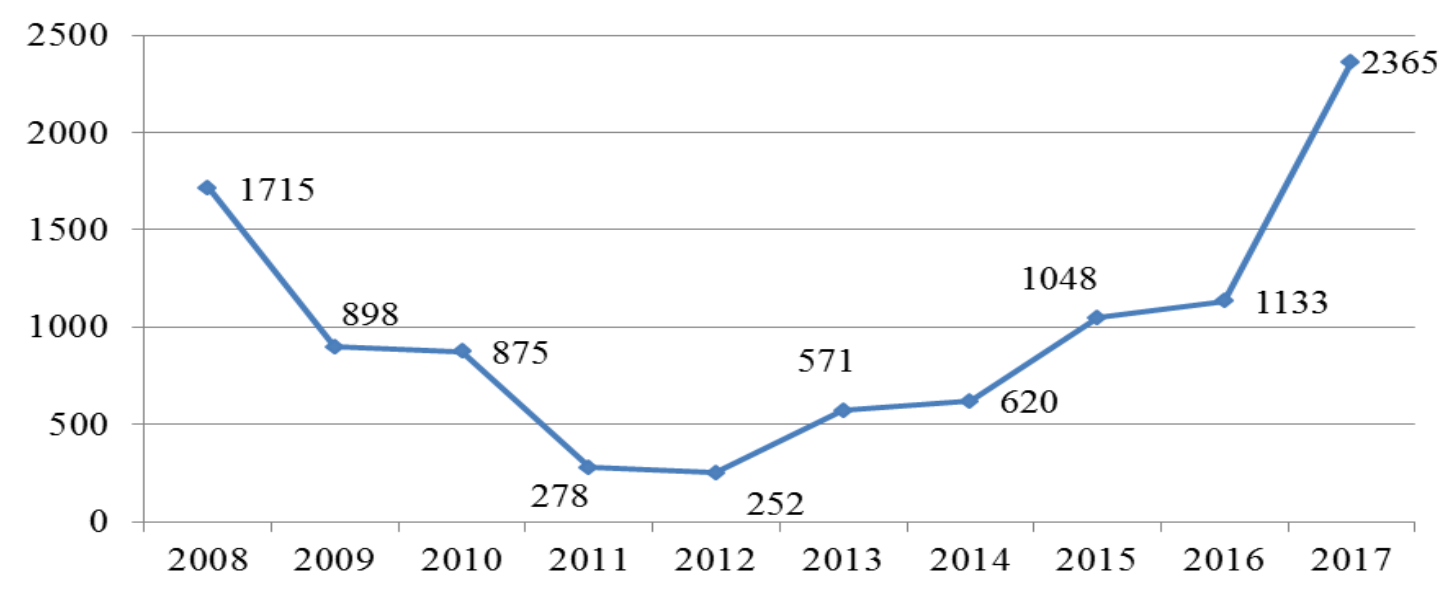

Fonte: Bacen, 2018.

Analisando o Gráfico 1, observa-se que há uma relação entre a quantidade de penalidades aplicadas e o total de decisões proferidas, no qual os anos de 2008 e 2017 foram os que mais tiverem decisões prolatadas e, consequentemente, mais penas impostas. Nestes anos, observa-se que a quantidade de decisões ficou bastante próxima ao número de penalidades aplicadas. Contudo, em determinados anos, é possível observar que uma decisão aplicou mais de uma penalidade, como ocorreu em 2012, no qual foram prolatadas 252 decisões e, naquele mesmo ano, foi aplicado um total de 806 penalidades. Isso significa que cada decisão proferida aplicou, em média, três penas. Da mesma forma, os anos de 2011 e 2014 tiveram, em média, a imposição de duas penalidades por decisão.

Os Gráficos 2, 3 e 4 expõem a quantidade de advertências, inabilitações e multas, respectivamente, aplicadas a cada tipo de instituição. Ressalta-se que todas as 23 proibições para atuar foram aplicadas em desfavor de auditores independentes ${ }^{6}$.

\footnotetext{
${ }^{6}$ Os auditores independentes são os responsáveis por assegurar a credibilidade das demonstrações financeiras de determinada instituição.
} 
Gráfico 2 - Advertências por instituição (2008 a 2017)

\section{ADVERTÊNCIAS}

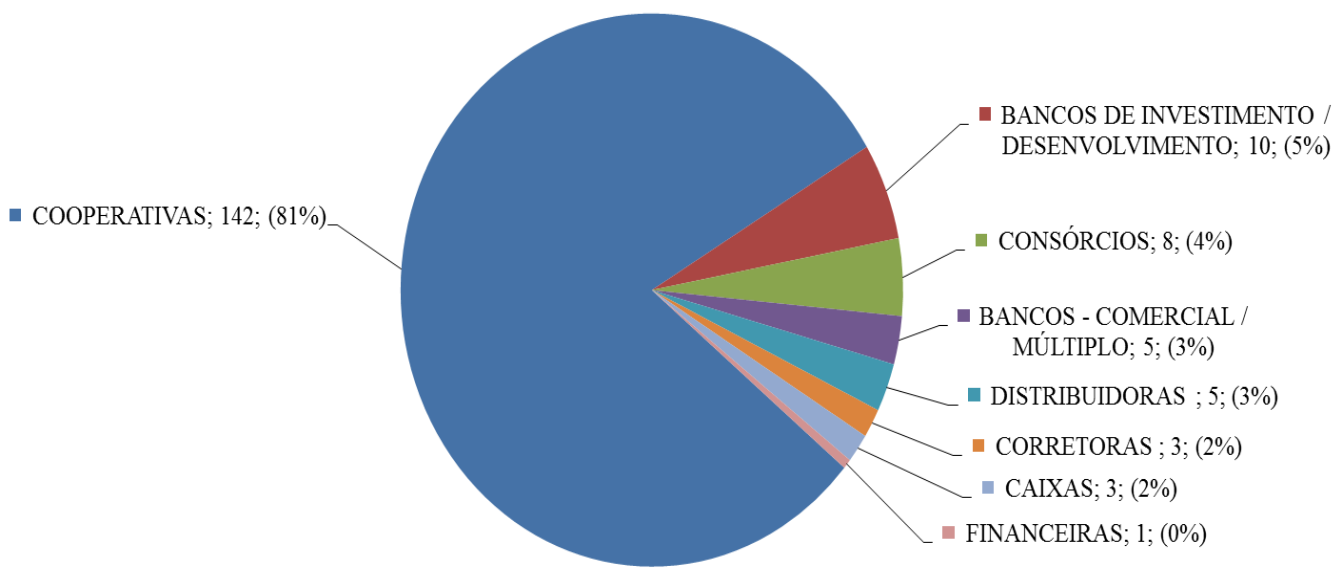

Fonte: Bacen, 2018.

Infere-se do Gráfico 2 que do total de 177 advertências impostas pelo Banco Central entre 2008 e 2017, 142 delas, ou seja, 81\% foram aplicadas contra as cooperativas. Da mesma forma, as cooperativas também foram as instituições que apresentaram o maior número de inabilitações. Isso porque do total de 2.043 penas de inabilitações, 1.542 , ou seja, 75\% foram aplicadas contra as cooperativas. Cumpre destacar que o ano de 2012 foi o que apresentou maior ocorrência tanto de advertências quanto de inabilitações.

Gráfico 3 - Inabilitações por instituição (2008 a 2017)

\section{INABILITAÇÕES}

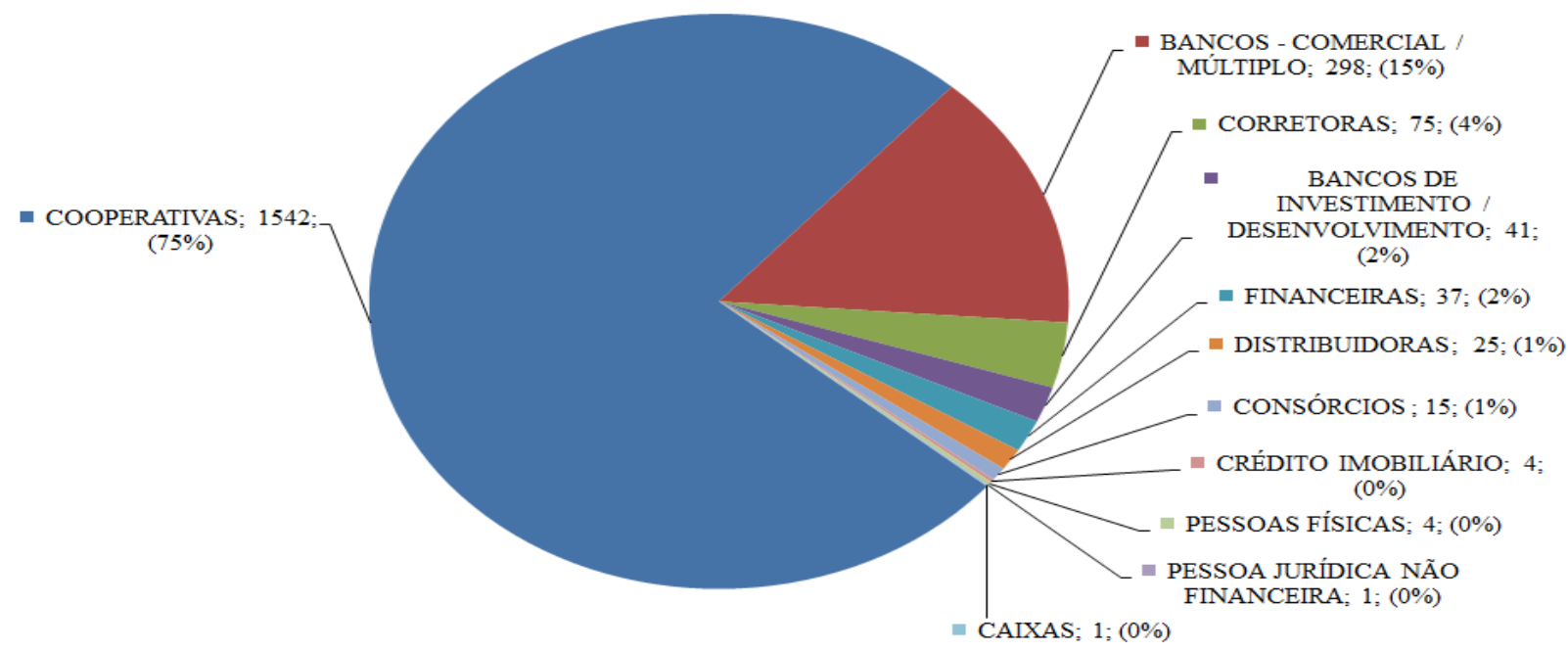

Fonte: Bacen, 2018. 
O aumento das aplicações de advertências e de inabilitações contra as cooperativas já vinha sendo percebido desde 2011. Tal aumento pode ser reflexo da entrada em vigor da Resolução n. 3.859 do Banco Central, de 27 de maio de 2010, que alterou e consolidou as normas referentes à constituição e ao funcionamento das cooperativas de crédito (BACEN, 2010).

Gráfico 4 - Multas por instituição (2008 a 2017)

MULTAS

- PESSOAS FÍSICAS; 4829; $(50 \%)$

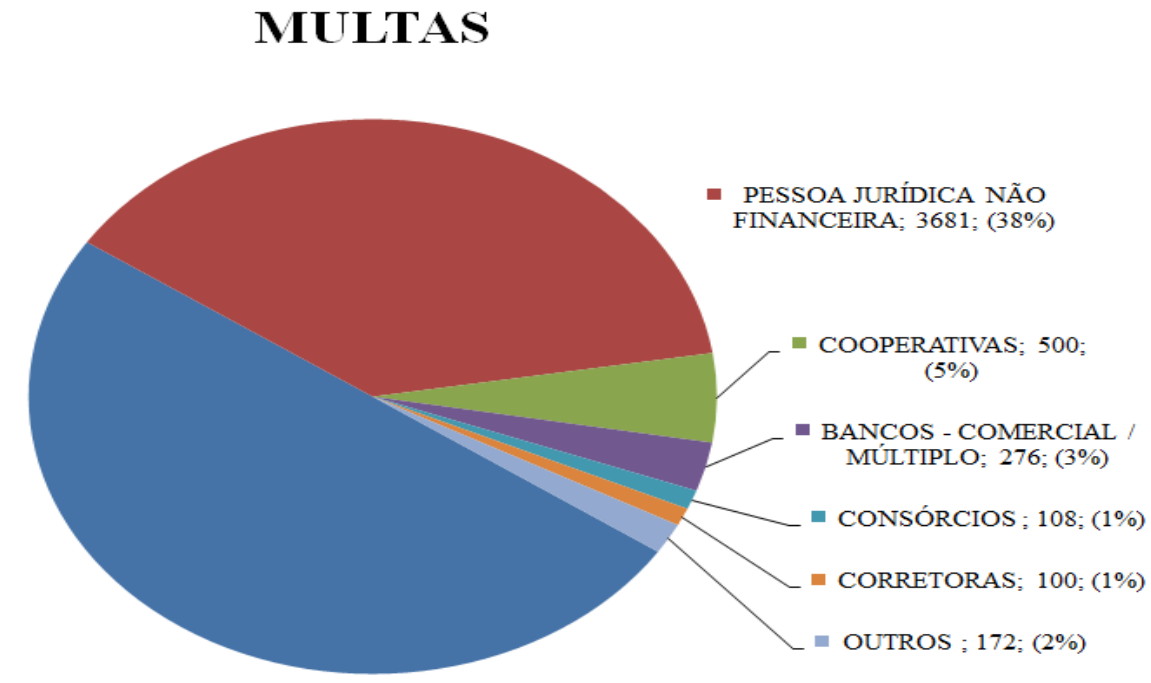

Fonte: Bacen, 2018.

Com relação à aplicação de multas, as quais são as penalidades mais utilizadas pelo Bacen, observa-se que as pessoas físicas foram as mais penalizadas, seguidas das pessoas jurídicas não financeiras. Metade das multas foi imposta às pessoas físicas, enquanto $38 \%$ foram aplicadas contra as pessoas jurídicas não financeiras. Percebe-se que as cooperativas aparecem aqui novamente, sendo elas posicionadas em terceiro lugar das instituições que mais recebem multas, sendo-lhes aplicadas $5 \%$ das penalidades.

Um dos possíveis motivos para essa grande participação das cooperativas tanto no número de advertências, inabilitações, quanto de multas pode ser explicado pela elevada quantidade destas instituições em funcionamento no país, como é possível observar na Tabela 2, a seguir exposta. 
Tabela 2 - Tipo e quantidade de instituições financeiras em funcionamento no país (até dezembro de 2017)

\begin{tabular}{|l|r|}
\hline Tipo de instituição & Quantidade em funcionamento no país \\
\hline Sociedade Distribuidora de Títulos e Valores Mobiliários & 94 \\
\hline Sociedade Corretora de Títulos e Valores Mobiliários & 72 \\
\hline Sociedade Corretora de Câmbio & 60 \\
\hline Sociedade de Crédito, Financiamento e Investimento & 56 \\
\hline Sociedade de Crédito ao Microempreendedor & 38 \\
\hline Sociedade de Arrendamento Mercantil & 23 \\
\hline Agência de Fomento & 16 \\
\hline Banco de Investimento & 13 \\
\hline Companhia Hipotecária & 7 \\
\hline Banco de Desenvolvimento & 3 \\
\hline Sociedade de Crédito Imobiliário - Repassadora & 2 \\
\hline Associação de Poupança e Empréstimo & 1 \\
\hline BNDES & 1 \\
\hline Banco do Brasil - Banco Múltiplo & 1 \\
\hline Banco Múltiplo & 128 \\
\hline Banco Comercial & 14 \\
\hline Caixa Econômica Federal & 1 \\
\hline Banco Múltiplo Cooperativo & 2 \\
\hline Banco de Câmbio & 3 \\
\hline Banco Comercial Estrangeiro - Filial no país & 6 \\
\hline Cooperativas & 1006 \\
\hline Administradoras de Consórcios & 156 \\
\hline Conglomerados & 97 \\
\hline
\end{tabular}

Fonte: Bacen, 2018.

Da Tabela 2 é possível verificar que existiam até dezembro de 2017, 1.006 cooperativas em funcionamento no país, sendo, portanto, o tipo de instituição com maior quantidade atuante até aquela data.

Adiante, os Gráficos 5 e 6 apresentam os históricos das multas aplicadas às pessoas físicas e jurídicas não financeiras no período em questão. 
Gráfico 5 - Quantidade de multas aplicadas às pessoas físicas (2008 a 2017)

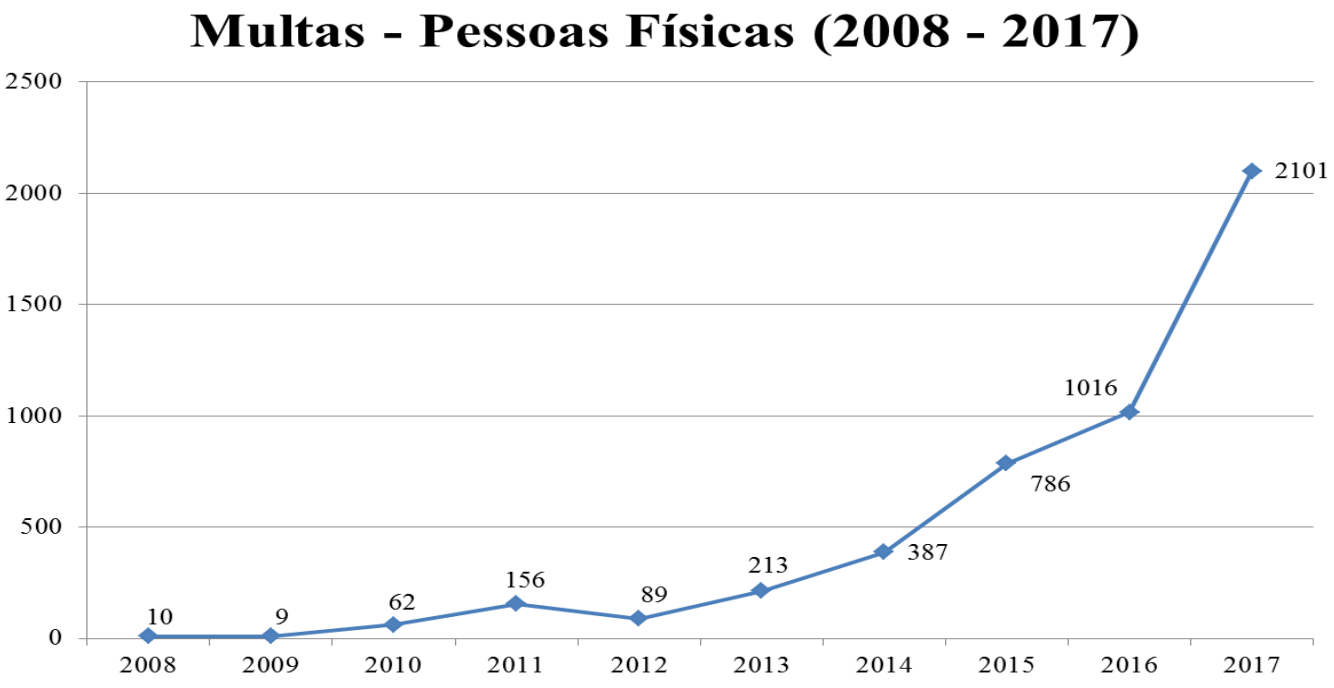

Fonte: Bacen, 2018.

Gráfico 6 - Quantidade de multas aplicadas às pessoas jurídicas não financeiras (2008 a 2018)

\section{Multas - Pessoas Jurídicas Não Financeiras (2008 - 2017)}

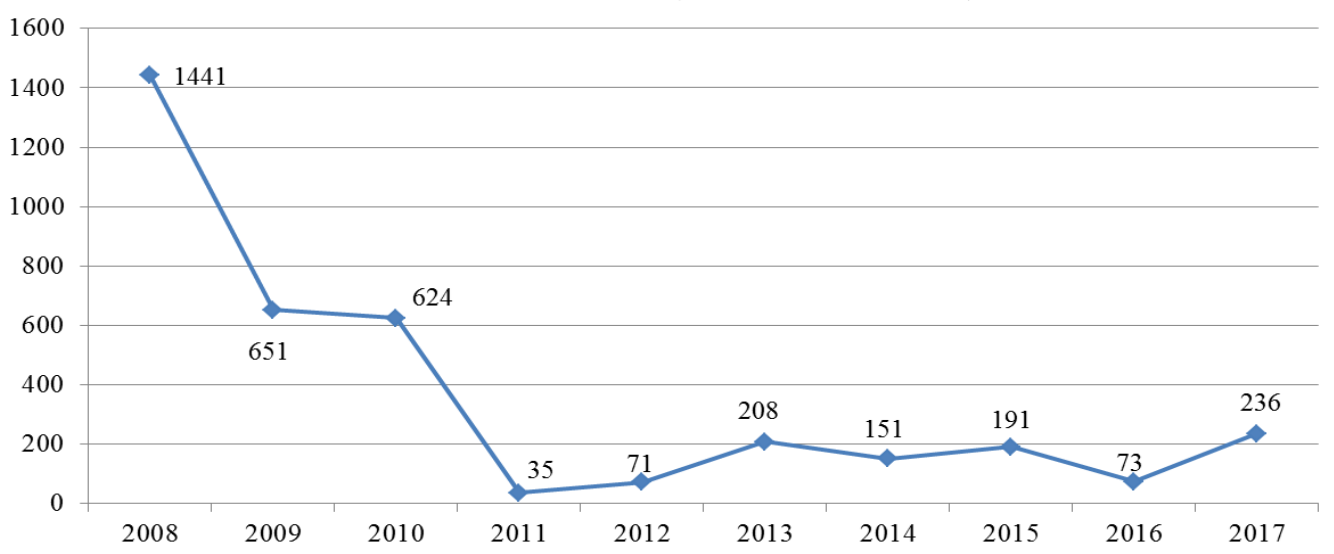

Fonte: Bacen, 2018.

Com relação ao Gráfico 5, observa-se que o número de multas aplicadas às pessoas físicas vem crescendo desde 2012. Do ano de 2016 para o de 2017 a quantidade de multas dobrou, sendo que 2016 já havia apresentado um número bastante elevado, de 1.016 penalidades impostas naquele ano. Assim, o ano de 2017 apresentou o maior número de imposição de multas contra as pessoas físicas, no qual foram aplicadas 2.101 penas. 
Em contrapartida, a quantidade de multas aplicadas em desfavor das pessoas jurídicas não financeiras reduziu no período de estudo, conforme visualizado no Gráfico 6. Verificase que 2008 foi o ano com a maior imposição de multas aplicadas às pessoas jurídicas não financeiras, com um total de 1.441 multas. A partir de então, esse número foi reduzindo e, atualmente, são aplicadas em torno de 100 a 200 multas às pessoas jurídicas não financeiras.

Mostra-se importante, neste momento, apresentar o valor das multas aplicadas no período de 2008 a 2017, a fim de realizar um comparativo entre os valores ao longo do tempo. Para tanto, são expostos a seguir os valores em termos reais, descontado o IPCA acumulado do período, tendo como base o ano de 2008, conforme expressa o Gráfico 7.

Gráfico 7 - Valor total das multas aplicadas em termos reais (base em 2008)

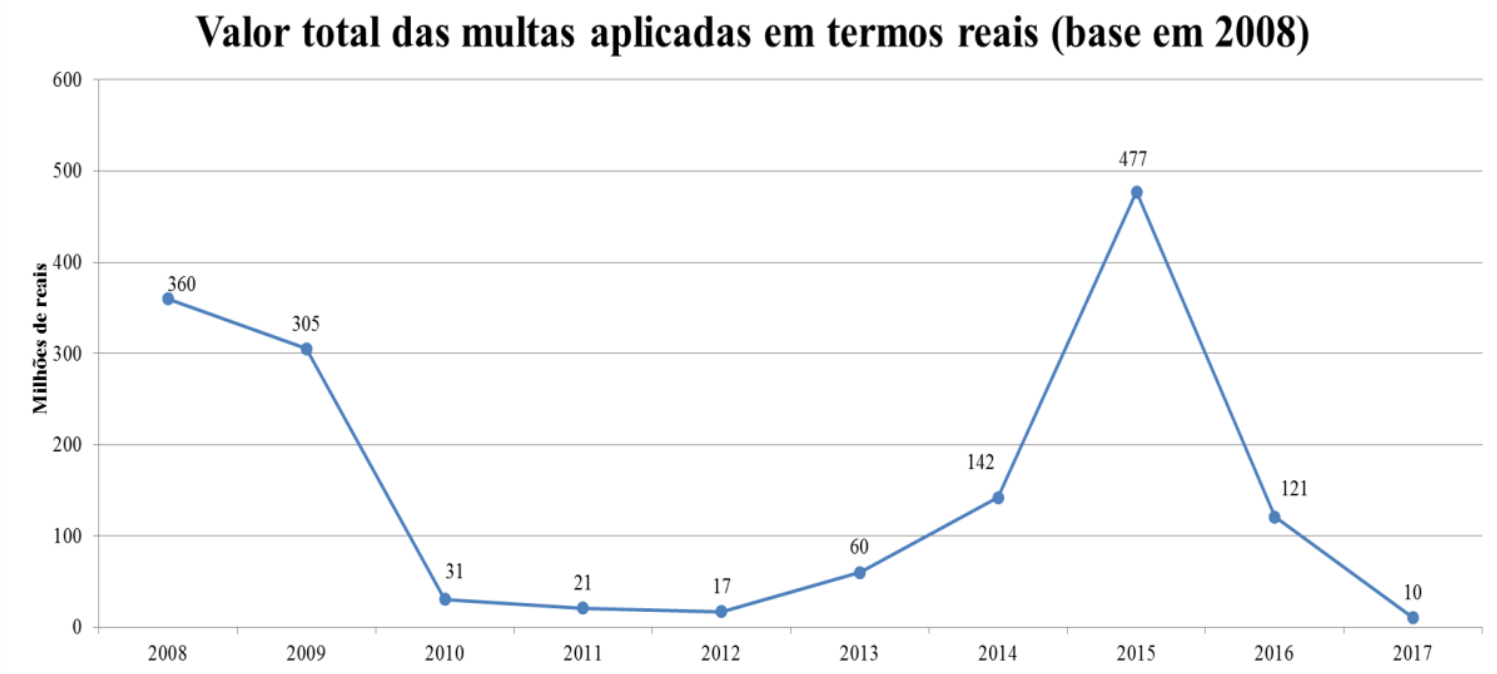

Fonte: Bacen, 2018.

Da análise dos gráficos, é possível verificar que o ano de 2015 foi o que apresentou o maior valor em termos reais do período em estudo. O segundo maior valor das multas ocorreu no ano de 2008. Uma possível explicação para este resultado foi o desdobramento das operações judiciais, que verificou um grande esquema de corrupção do Brasil.

O Anexo II apresenta as tabelas com os valores totais aplicados contra cada instituição financeira. Assim, é possível concluir que o aumento do valor no ano de 2015 ocorreu em razão de 43 multas que foram aplicadas às corretoras naquele ano, e que alcançaram o valor real aproximado de $\mathrm{R} \$ 365.000 .000,00$, somados à ilícitos cambiais cometidos por pessoas jurídicas não financeiras que contribuíram também para o montante ser o maior do período observado. Ressalta-se, ainda, que o valor elevado obtido no ano de 2008 também ocorreu 
em razão das multas decorrentes de ilícitos cambiais praticados pelas pessoas jurídicas não financeiras.

Importante destacar que apesar de 2017 ter sido o ano em que foram aplicadas maior quantidade de multas, naquele ano o valor total das mesmas não foi tão elevado, sendo, inclusive, o menor observado desde 2008. Isso pode ter ocorrido, porque a maioria das multas de 2017 foi imposta em desfavor das pessoas físicas; concluindo-se daí, que o valor médio de multas aplicadas a essas pessoas foi bastante inferior ao valor médio imposto contra outras instituições ou contra as pessoas jurídicas não financeiras.

Por fim, é possível afirmar que nos primeiros anos analisados havia uma maior tendência de aplicação das multas às pessoas jurídicas não financeiras, as quais também tinham que despender maior volume monetário para pagamento das multas, que possuíam um valor médio bastante elevado. Contudo, nos últimos anos, verificou-se o aumento de aplicação de multas às pessoas físicas, contra as quais foram impostos valores médios menores do que aqueles aplicados contra as instituições financeiras. Salienta-se que não existe um padrão nos valores das multas, posto que o Banco Central avalia cada caso concreto e aplica os valores de acordo com as particularidades e irregularidades verificadas.

O Gráfico 8 apresenta os tipos de processo, sendo considerados apenas os processos de fluxo de capitais ${ }^{7}$, cambiais $^{8}$ e financeiros ${ }^{9}$, tendo em vista que foram os que mais ensejaram a aplicação das multas nos últimos anos. Destaca-se, no entanto, que no ano de 2017 não foi registrado nenhum processo cambial.

\footnotetext{
${ }^{7}$ Processos relacionados ao descumprimento de normas relativas ao fluxo de capitais internacional, ou seja, pessoas físicas ou jurídicas que possuem ativos no exterior e não os declararam dentro dos prazos e condições estabelecidas pelo Banco Central do Brasil.

${ }^{8}$ Processos que decorrem de operações de câmbio ilegítimas, ou seja, operações cambiais não autorizadas que tem como objetivo a evasão de divisas. Além disso, o Decreto n. 23.258/33 estabelece que: "Art. $1^{\circ}$ São consideradas operações de câmbio ilegítimas as realizadas entre bancos, pessoas naturais ou jurídicas, domiciliadas ou estabelecidas no país, com quaisquer entidades do exterior, quando tais operações não transitem pelos bancos habilitados a operar em câmbio, mediante prévia autorização da fiscalização bancária a cargo do Banco do Brasil. Art. $2^{\circ}$ São também consideradas operações de câmbio ilegítimas as realizadas em moeda brasileira por entidades domiciliadas no país, por conta e ordem de entidades brasileiras ou estrangeiras domiciliadas ou residentes no exterior. Art. $3^{\circ}$ É passível de penalidade o aumento de preço de mercadorias importadas para obtenção de coberturas indevidas".

${ }^{9}$ Processos referentes a ilícitos financeiros, como a "lavagem" e ocultação de bens, direitos e valores, regulamentada pela Lei n. 9.613/98, além de outras infrações como o descumprimento da obrigação de enviar informações e manter os cadastros atualizados no Banco Central, o exercício de atividades de gerência sem a autorização do Bacen, dentre outros ilícitos previstos na Lei n. 7.492/86.
} 
Gráfico 8 - Tipo de processo multas (2008 a 2017)

\section{TIPO DE PROCESSO - MULTAS (2008 - 2017)}
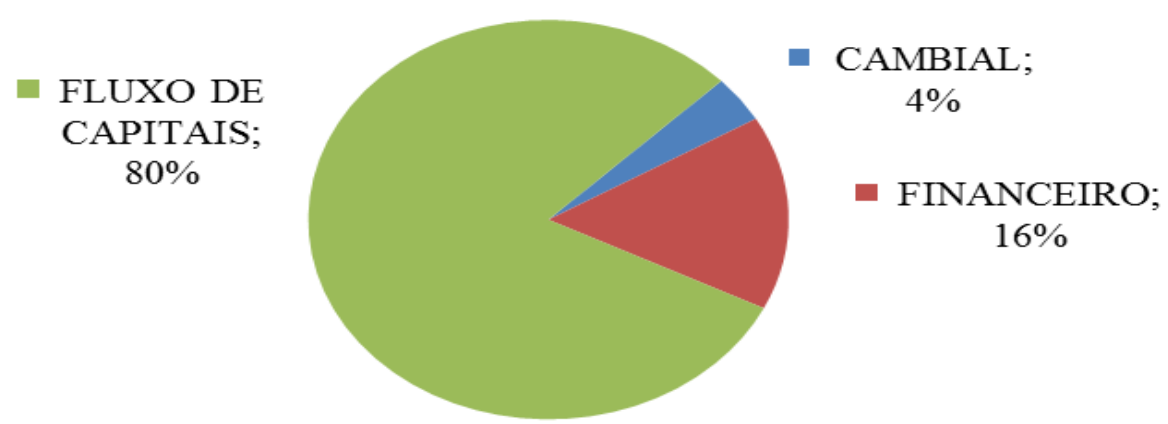

Fonte: Bacen, 2018.

O Gráfico 8 indica, ainda, que $80 \%$ das multas aplicadas foram decorrentes de processos relacionados aos fluxos de capitais. Observa-se que a maioria desses processos se refere à manutenção de contas no exterior por pessoas físicas ou pessoas jurídicas não financeiras que não declararam, nos termos e prazos fixados pelo Banco Central, a existência de recursos em contas fora do país.

Tabela 3 - Recursos julgados pelo Conselho de Recursos do SFN (a partir de 01.01.2011)

\begin{tabular}{|c|c|c|}
\hline Resultado & Quant. & $\%$ \\
\hline Decisões confirmadas & 645 & $75,4 \%$ \\
\hline Decisões modificadas - aumento do prazo de afastamento & 0 & $0 \%$ \\
\hline Decisões modificadas - convolação em advertência & 9 & $1,1 \%$ \\
\hline Decisões modificadas - convolação em arquivamento & 26 & $3,0 \%$ \\
\hline Decisões modificadas - convolação em multa & 66 & $7,7 \%$ \\
\hline Decisões modificadas - convolação em suspensão & 0 & $0 \%$ \\
\hline Decisões modificadas - redução do prazo de afastamento & 108 & $12,6 \%$ \\
\hline Outros (nulidade/extinção) & 1 & $0,1 \%$ \\
\hline Total & 855 & $100 \%$ \\
\hline
\end{tabular}

Fonte: Bacen, 2018.

Importante destacar que todas as infrações que resultaram em proibições para atuar foram decorrentes de processos financeiros, assim como, considerando-se apenas os três processos apontados, todas as advertências. Já as inabilitações, em sua grande maioria originaram-se de processos financeiros, e parcela ínfima decorreu de processos cambiais. 
A Tabela 3 expõe os dados das decisões que aplicaram inabilitações, suspensões ou proibições para atuar, a partir de 2011, e que foram recorridas ao Conselho de Recursos de SFN, mostrando o resultado obtido após o julgamento em $2^{\mathrm{a}}$ instância.

A Tabela 3 retrata que $75,4 \%$ das decisões recorridas foram confirmadas em $2^{\mathrm{a}}$ instância. Das que foram modificadas, observa-se que a maioria delas, 12,6\%, beneficiou o infrator, porquanto reduziu o prazo de seu afastamento. Destaca-se que nenhum recurso resultou em piora ao apenado, ou seja, em nenhum caso ocorreu aumento do prazo do seu afastamento. Ademais, 7,7\% das decisões de inabilitação, suspensão ou proibição para atuar foram convertidas em multas e $3 \%$ foram arquivadas.

\section{CONSIDERAÇÕES FINAIS}

O sistema financeiro apresenta um risco inerente ao setor, que é o risco sistêmico. Esse ocorre em razão das externalidades negativas que podem surgir quando uma instituição financeira quebra. Isso porque, quando possuem confiança de que os bancos honrarão seus compromissos, os agentes econômicos são indiferentes entre manter moeda legal ou realizar depósitos. Porém, a falência de um banco acaba criando desconfianças nos agentes, os quais promovem as corridas bancárias, a fim de sacarem os seus recursos o mais rápido possível. Assim, este fenômeno acaba contagiando, portanto, outras instituições, podendo, inclusive, causar impactos negativos em toda uma economia.

$\mathrm{Na}$ finalidade de minimizar o risco sistêmico, bem como as assimetrias informacionais, e garantir maior solidez e eficiência do Sistema Financeiro Nacional, o Estado deve intervir, por meio do Banco Central, o qual tem como atribuição realizar a regulação, a fiscalização e o monitoramento das instituições financeiras. A regulação exercida pelo Bacen pode ser: sistêmica, na qual já foram verificadas fragilidades em alguma instituição financeira e a mesma é realizada para não deixar que haja o seu alastramento a outras entidades ou; prudencial, cujos mecanismos utilizados são preventivos à ocorrência de crises.

O Bacen, na qualidade de órgão supervisor, deve, portanto, fiscalizar o cumprimento das normas e adequações exigidas. No entanto, caso verifique alguma irregularidade ele pode instaurar processo administrativo disciplinar e aplicar as penalidades que entender necessárias para que o infrator se abstenha de praticar atos que coloquem em risco a estabilidade do SFN.

Diante disto, o presente trabalho analisou os históricos das penalidades aplicadas pelo Bacen, contra as instituições que descumprem as normas e recomendações existentes. É 
possível concluir que as multas foram os tipos de penas que mais utilizadas no período de 2008 a 2017. As segundas penalidades mais aplicadas foram as inabilitações, seguidas das advertências e, por último das proibições para atuar.

Dentre os tipos de instituição que receberam as penalidades, verificou-se que as advertências e inabilitações em sua maioria foram aplicadas contra as cooperativas, que eram, até dezembro de 2017, o tipo de instituição em funcionamento em maior número no cenário nacional. Ademais, todas as proibições para atuar foram impostas em desfavor dos auditores independentes.

No que se refere às multas, foi possível observar que as pessoas físicas foram as que mais foram penalizadas, seguidas das pessoas jurídicas não financeiras. Além disso, observou-se um aumento nos últimos anos de aplicação desta pena para as pessoas físicas, sendo que 2017 apresentou o maior número de multas do período em questão. Por outro lado, verificou-se uma redução, ao longo do intervalo estudado, da quantidade de multas aplicadas contra as pessoas jurídicas não financeiras.

Importante ressaltar, ainda, que apesar do ano de 2017 ter registrado a maior quantidade de multas impostas, esse ano foi o que obteve o menor valor total das multas até então. Um dos motivos para isso é o de que quase a totalidade dessas multas foi imposta às pessoas físicas, sendo possível extrair daí que o valor médio de multas aplicadas contra essas pessoas é inferior àquele imposto a outras instituições.

A maioria dos processos que resultara em multas decorreu de processos de fluxos de capitais. Já os processos de advertência e proibição para atuar foram processos financeiros, assim como, os que tiveram como resultado a inabilitação, constatando-se apenas uma pequena quantidade de processos cambiais que inabilitaram os infratores.

\section{REFERÊNCIAS}

BANCO CENTRAL DO BRASIL. Resolução n. 3.859, de 27 de maio de 2010. Altera e consolida as normas relativas à constituição e ao funcionamento de cooperativas de crédito. https://www.bcb.gov.br/pre/normativos/res/2010/pdf/res_3859_v4_p.pdf. Acesso em: 11 dez. 2018.

BANCO CENTRAL DO BRASIL. Recomendações de Basiléia. 2018a. Disponível em: https://www.bcb.gov.br/fis/supervisao/basileia.asp. Acesso em: 21 out. 2018.

BANCO CENTRAL DO BRASIL. Sobre os processos administrativos sancionadores no

Banco Central do Brasil.2018b. Disponível em:


https://www4.bcb.gov.br/fis/pad/port/menu/processoadministrativo.asp. Acesso em: 31 nov. 2018.

BANCO CENTRAL DO BRASIL. Relação de instituições em funcionamento no país. 2018c. Disponível em: https://www.bcb.gov.br/fis/info/instituicoes.asp?idpai=INFCAD. Acesso em 11 dez. 2018.

BRASIL. Decreto n. 23.258, de 19 de outubro de 1933. Dispõe sobre as operações de câmbio, e dá outras providências. Disponível em: http://www.planalto.gov.br/ccivil_03/decreto/1930-1949/D23258.htm. Acesso em: 9 dez. 2018.

BRASIL. Lei ${ }^{\circ}$ 6.024, de 13 de março de 1974. Dispõe sobre a intervenção e a liquidação extrajudicial de instituições financeiras, e dá outras providências. Disponível em: http://www.planalto.gov.br/ccivil_03/LEIS/L6024.htm. Acesso em: 24 out. 2018.

BRASIL. Lei n. 7.492, de 16 de junho de 1986. Define os crimes contra o sistema financeiro nacional, $e$ dá outras providências. Disponível em: http://www.planalto.gov.br/ccivil_03/leis/L7492.htm. Acesso em: 10 dez. 2018.

BRASIL. Decreto-Lei ${ }^{\circ} 2.321$, de 25 de fevereiro de 1987. Institui, em defesa das finanças públicas, regime de administração especial temporária, nas instituições financeiras privadas e públicas não federais, e dá outras providências. Disponível em: http://www.planalto.gov.br/ccivil_03/decreto-lei/Del2321.htm. Acesso em: 24 out. 2018.

BRASIL. Lei n. 9.613, de 3 de março de 1998. Dispõe sobre os crimes de "lavagem" ou ocultação de bens, direitos e valores; a prevenção da utilização do sistema financeiro para os ilícitos previstos nesta Lei; cria o Conselho de Controle de Atividades Financeiras - COAF, e dá outras providências. Disponível em: http://www.planalto.gov.br/ccivil_03/LEIS/L9613.htm. Acesso em 9 dez. 2018.

BRASIL. Resolução $\mathrm{n}^{\circ} 4.222$, de 23 de maio de 2013. Dispõe sobre as contribuições a serem pagas pelas instituições associadas, as condições para dispor da garantia especial, os tipos de instituições associadas e o estatuto e o regulamento do Fundo Garantidor de Créditos (FGC). Disponível em: https://www.bcb.gov.br/pre/normativos/busca/downloadNormativo.asp?arquivo=/Lists/Nor mativos/Attachments/48942/Res_4222_v8_P.pdf. Acesso em: 22 out. 2018.

BRASIL. Lei $\mathrm{n}^{\circ} 13.506$, de 13 de novembro de 2017. Dispõe sobre o processo administrativo sancionador na esfera de atuação do Banco Central do Brasil e da Comissão de Valores Mobiliários e dá outras providências. Disponível em: http://www.planalto.gov.br/ccivil_03/_Ato2015-2018/2017/Lei/L13506.htm. Acesso em: 24 out. 2018.

CARVALHO, F. J. C. Inovação financeira e regulamentação prudencial: da regulação de liquidez aos Acordos de Basileia. In: SOBREIRA, R. (Org.). Regulação financeira e bancária. São Paulo: Editora Atlas, 2005. p. 121-139. Disponível em: http://www.ie.ufrj.br/moeda/pdfs/inovacao_financeira_e_regulacao.pdf. Acesso em 15 nov. 2018. 
CARVALHO, F. J. C. et al. Economia monetária financeira: teoria e política. Rio de Janeiro: Elsevier, 2007 - 9a reimpressão.

CARVALHO, F. J. C. Reformas financeiras para apoiar o desenvolvimento. Brasília, DF: CEPAL. Escritório no Brasil/IPEA, 2010. Disponível em: http://www.ipea.gov.br/portal/images/stories/PDFs/TDs/td_1532.pdf. Acesso em: 29 nov. 2018.

MISHKIN, F. S. Prudential supervision: why is it important and what are the issues. In: MISHKIN, F. S. (Org.) Prudential supervision: what works and what doesn't. Chicago: The University of Chicago Press, 2001.

YAZBEK, O. Regulação do mercado financeiro e de capitais. $2^{a}$ reimpressão. Rio de Janeiro: Elsevier, 2007.

\section{ANEXO I - PENALIDADES APLICADAS POR ANO (2008 A 2017)}

Tabela 1 - Penalidades aplicadas no ano de 2008

\begin{tabular}{|c|c|c|c|c|c|c|}
\hline \multicolumn{7}{|c|}{ Penalidades aplicadas no ano de 2008} \\
\hline Tipo de instituição & ADVERTÊNCIA & ARQUIVAMENTO & INABILIT AÇÃO & MULTA & PROIBIÇÃO PARA ATUAR & Total \\
\hline Auditores Independentes & 0 & 0 & 0 & 4 & 4 & 8 \\
\hline Bancos - Comercial / Múltiplo & 0 & 14 & 41 & 23 & 0 & 78 \\
\hline Bancos de Investimento / Desenvolvimento & 0 & 1 & 8 & 2 & 0 & 11 \\
\hline Consórcios & 0 & 1 & 0 & 6 & 0 & 7 \\
\hline Cooperativas & 7 & 32 & 148 & 51 & 0 & 238 \\
\hline Corretoras & 0 & 0 & 2 & 1 & 이 & 3 \\
\hline Crédito Imobiliário & 0 & 1 & 2 & 1 & 0 & 4 \\
\hline Distribuidoras & 0 & 0 & 2 & 2 & 0 & 4 \\
\hline Financeiras & 1 & 2 & 2 & 0 & 0 & 5 \\
\hline Mercado Marginal - Consórcio & 0 & 0 & 0 & 1 & 0 & 1 \\
\hline Pessoa Jurídica Não Financeira & 0 & 346 & 0 & 1419 & 0 & 1765 \\
\hline Pessoas Físicas & 0 & 4 & 0 & 7 & 0 & 11 \\
\hline \multicolumn{7}{|l|}{ Ilícitos cambiais } \\
\hline Bancos - Comercial / Múltiplo & 0 & 0 & 0 & 2 & 0 & 2 \\
\hline Pessoa Jurídica Não Financeira & 0 & 8 & 0 & 22 & 0 & 30 \\
\hline Pessoas Físicas & 0 & 0 & 0 & 3 & 0 & 3 \\
\hline Total & 8 & 409 & 205 & 1544 & 4 & 2170 \\
\hline
\end{tabular}

Fonte: Bacen, 2018.

Tabela 2 - Penalidades aplicadas no ano de 2009

\begin{tabular}{|c|c|c|c|c|c|c|}
\hline & Penalidades a & plicadas no ano de & 2009 & & & \\
\hline Tipo de instituição & ADVERTÊNCIA & ARQUIVAMENTO & INABILIT AÇÃO & MULTA & PROIBIÇÃO PARA ATUAR & Total \\
\hline Arrendamento Mercantil & 0 & 1 & 0 & 0 & 0 & 1 \\
\hline Auditores Independentes & 0 & 0 & 0 & 1 & 1 & 2 \\
\hline Bancos - Comercial / Múltiplo & 0 & 4 & 34 & 7 & 0 & 45 \\
\hline Bancos de Investimento / Desenvolvimento & 3 & 0 & 4 & 4 & 0 & 11 \\
\hline Consórcios & 0 & 0 & 0 & 12 & 0 & 12 \\
\hline Cooperativas & 7 & 16 & 71 & 20 & 0 & 114 \\
\hline Corretoras & 0 & 0 & 5 & 3 & 0 & 8 \\
\hline Distribuidoras & 0 & 0 & 1 & 2 & 0 & 3 \\
\hline Financeiras & 0 & 2 & 0 & 0 & 0 & 2 \\
\hline Mercado Marginal - Consórcio & 0 & 0 & 0 & 3 & 0 & 3 \\
\hline Mercado Marginal - Lei 4.595 & 0 & 2 & 0 & 0 & 0 & 2 \\
\hline Pessoa Jurídica Não Financeira & 0 & 233 & 0 & 631 & 0 & 864 \\
\hline Pessoas Físicas & 0 & 3 & 0 & 8 & 0 & 11 \\
\hline Ilícitos cambiais & & & & & & \\
\hline Pessoa Jurídica Não Financeira & 0 & 1 & 0 & 20 & 0 & 21 \\
\hline Pessoas Físicas & 0 & 0 & 0 & 1 & 0 & 1 \\
\hline Total & 10 & 262 & 115 & 712 & 1 & 1100 \\
\hline
\end{tabular}

Fonte: Bacen, 2018.

Tabela 3 - Penalidades aplicadas no ano de 2010 


\begin{tabular}{|c|c|c|c|c|c|}
\hline \multicolumn{6}{|c|}{ Penalidades aplicadas no ano de 2010} \\
\hline Tipo de instituiç̣̃o & ADVERTÊNCIA & ARQUIVAMENTO & INABILIT ACCÃO & MULTA & Total \\
\hline Bancos - Comercial / Múltiplo & 0 & 7 & 29 & 23 & 59 \\
\hline Bancos de Investimento / Desenvolvimento & 0 & 4 & 4 & 2 & 10 \\
\hline Consórcios & 0 & 0 & 0 & 4 & 4 \\
\hline Cooperativas & 14 & 4 & 91 & 54 & 163 \\
\hline Corretoras & 1 & 2 & 2 & 2 & 7 \\
\hline Distribuidoras & 1 & 0 & 1 & 3 & 5 \\
\hline Financeiras & 0 & 0 & 2 & 1 & 3 \\
\hline Mercado Marginal - Consórcio & 0 & 0 & 0 & 2 & 2 \\
\hline Mercado Marginal - Lei 4.595 & 0 & 0 & 0 & 2 & 2 \\
\hline Pessoa Jurídica Não Financeira & 0 & 250 & 0 & 619 & 869 \\
\hline Pessoas Físicas & 0 & 8 & 0 & 62 & 70 \\
\hline \multicolumn{6}{|l|}{ Ilícitos cambiais } \\
\hline Pessoa Jurídica Não Financeira & 0 & 1 & 0 & 5 & 6 \\
\hline Total & 16 & 276 & 129 & 779 & 1200 \\
\hline
\end{tabular}

Fonte: Bacen, 2018.

Tabela 4 - Penalidades aplicadas no ano de 2011

\begin{tabular}{|c|c|c|c|c|c|c|}
\hline \multicolumn{7}{|c|}{ Penalidades aplicadas no ano de 2011} \\
\hline Tipo de instituição & ADVERTÊNCIA & ARQUIVAMENTO & INABILIT AÇÃOO & MULTA & PROIBIÇÃO PARA ATUAR & Total \\
\hline Auditores Independentes & 0 & 3 & 0 & 1 & 1 & 5 \\
\hline Bancos - Comercial / Múltiplo & 0 & 34 & 36 & 13 & 0 & 83 \\
\hline Consórcios & 0 & 0 & 0 & 15 & 0 & 15 \\
\hline Cooperativas & 24 & 21 & 253 & 40 & 0 & 338 \\
\hline Corretoras & 0 & 0 & 0 & 3 & 0 & 3 \\
\hline Crédito Imobiliário & 0 & 1 & 2 & 2 & 0 & 5 \\
\hline Distribuidoras & 3 & 0 & 2 & 3 & 0 & 8 \\
\hline Financeiras & 0 & 0 & 0 & 4 & 0 & 4 \\
\hline Pessoa Jurídica Não Financeira & 0 & 6 & 0 & 29 & 0 & 35 \\
\hline Pessoas Físicas & 0 & 6 & 0 & 156 & 0 & 162 \\
\hline \multicolumn{7}{|l|}{ Ilícitos cambiais } \\
\hline Pessoa Jurídica Não Financeira & 0 & 2 & 0 & 6 & 0 & 8 \\
\hline Total & 27 & 73 & 293 & 272 & 1 & 666 \\
\hline
\end{tabular}

Fonte: Bacen, 2018.

Tabela 5 - Penalidades aplicadas no ano de 2012

\begin{tabular}{|c|c|c|c|c|c|c|}
\hline \multicolumn{7}{|c|}{ Penalidades aplicadas no ano de 2012} \\
\hline Tipo de instítuição & ADVERTÊNCIA & ARQUIVAMENTO & INABILIT AÇÃO & MULTA & PROIBIÇÃO PARA ATUAR & Total \\
\hline Auditores Independentes & 0 & 0 & 0 & 2 & 2 & 4 \\
\hline Bancos - Comercial / Múltiplo & 0 & 23 & 78 & 55 & 0 & 156 \\
\hline Bancos de Investimento / Desenvolvimento & 7 & 2 & 14 & 15 & 0 & 38 \\
\hline Consórcios & 4 & 2 & 0 & 13 & 0 & 19 \\
\hline Cooperativas & 26 & 44 & 340 & 25 & 0 & 435 \\
\hline Corretoras & 0 & 7 & 14 & 9 & 0 & 30 \\
\hline Distribuidoras & 1 & 1 & 17 & 9 & 0 & 28 \\
\hline Financeiras & 0 & 3 & 7 & 4 & 0 & 14 \\
\hline Mercado Marginal - Consórcio & 0 & 0 & 0 & 2 & 0 & 2 \\
\hline Mercado Marginal - Lei 4.595 & 0 & 0 & 0 & 2 & 0 & 2 \\
\hline Pessoa Jurídica Não Financeira & 0 & 9 & 0 & 70 & 0 & 79 \\
\hline Pessoas Físicas & 0 & 1 & 0 & 87 & 0 & 88 \\
\hline \multicolumn{7}{|l|}{ Ilícitos cambiais } \\
\hline Pessoa Jurídica Não Financeira & 0 & 0 & 0 & 1 & 0 & 1 \\
\hline Pessoas Físicas & 0 & 0 & 0 & 2 & 0 & 2 \\
\hline Total & 38 & 92 & 470 & 296 & 2 & 898 \\
\hline
\end{tabular}

Fonte: Bacen, 2018. 
Tabela 6 - Penalidades aplicadas no ano de 2013

\begin{tabular}{|c|c|c|c|c|c|c|}
\hline \multicolumn{7}{|c|}{ Penalidades aplicadas no ano de 2013} \\
\hline Tipo de instituição & ADVERTÊNCIA & ARQUIVAMENTO & INABILIT AÇÃOO & MULTA & PROIBIÇÃO PARA ATUAR & Total \\
\hline Auditores Independentes & 0 & 2 & 0 & 1 & 3 & 6 \\
\hline Bancos - Comercial / Múltiplo & 5 & 5 & 13 & 65 & 0 & 88 \\
\hline Bancos de Investimento / Desenvolvimento & 0 & 0 & 0 & 3 & 0 & 3 \\
\hline Consórcios & 0 & 0 & 0 & 16 & 0 & 16 \\
\hline Cooperativas & 16 & 31 & 172 & 33 & 0 & 252 \\
\hline Corretoras & 0 & 0 & 3 & 3 & 0 & 6 \\
\hline Crédito Imobiliário & 0 & 0 & 0 & 3 & 0 & 3 \\
\hline Financeiras & 0 & 5 & 10 & 7 & 0 & 22 \\
\hline Mercado Marginal - Lei 4.595 & 0 & 0 & 0 & 2 & 0 & 2 \\
\hline Pessoa Jurídica Não Financeira & 0 & 218 & 0 & 196 & 0 & 414 \\
\hline Pessoas Físicas & 0 & 9 & 0 & 204 & 0 & 213 \\
\hline \multicolumn{7}{|l|}{ Ilícitos cambiais } \\
\hline Corretoras & 0 & 0 & 0 & 4 & 0 & 4 \\
\hline Pessoa Jurídica Não Financeira & 0 & 0 & 0 & 12 & 0 & 12 \\
\hline Pessoas Físicas & 0 & 0 & 0 & 9 & 0 & 9 \\
\hline Total & 21 & 270 & 198 & 558 & 3 & 1050 \\
\hline
\end{tabular}

Fonte: Bacen, 2018.

Tabela 7 - Penalidades aplicadas no ano de 2014

\begin{tabular}{|c|c|c|c|c|c|c|}
\hline \multicolumn{7}{|c|}{ Penalidades aplicadas no ano de 2014} \\
\hline Tipo de instituição & ADVERTÊNCIA & ARQUIVAMENTO & INABILIT ACC̃̃O & MULTA & PROIBIÇÃO PARA ATUAR & Total \\
\hline Auditores Independentes & 0 & 1 & 0 & 8 & 11 & 20 \\
\hline Bancos - Comercial / Múltiplo & 0 & 3 & 49 & 14 & 0 & 66 \\
\hline Consórcios & 4 & 0 & 5 & 12 & 0 & 21 \\
\hline Cooperativas & 16 & 107 & 250 & 186 & 0 & 559 \\
\hline Corretoras & 0 & 0 & 9 & 14 & 0 & 23 \\
\hline Distribuidoras & 0 & 0 & 0 & 2 & 0 & 2 \\
\hline Mercado Marginal - Lei 4.595 & 0 & 0 & 0 & 2 & 0 & 2 \\
\hline Pessoa Jurídica Não Financeira & 0 & 25 & 0 & 122 & 0 & 147 \\
\hline Pessoas Físicas & 0 & 10 & 0 & 306 & 0 & 316 \\
\hline Sociedade de Crédito ao Microempreendedor & 0 & 0 & 0 & 3 & 0 & 3 \\
\hline \multicolumn{7}{|l|}{ Ilícitos cambiais } \\
\hline Bancos - Comercial / Múltiplo & 0 & 1 & 0 & 0 & 0 & 1 \\
\hline Corretoras & 0 & 1 & 3 & 1 & 0 & 5 \\
\hline Pessoa Jurídica Não Financeira & 0 & 1 & 0 & 29 & 0 & 30 \\
\hline Pessoas Físicas & 0 & 7 & 0 & 81 & 0 & 88 \\
\hline Total & 20 & 156 & 316 & 780 & 11 & 1283 \\
\hline
\end{tabular}

Fonte: Bacen, 2018.

Tabela 8 - Penalidades aplicadas no ano de 2015

\begin{tabular}{|c|c|c|c|c|c|c|}
\hline \multicolumn{7}{|c|}{ Penalidades aplicadas no ano de 2015} \\
\hline Tipo de instituição & ADVERTÊNCIA & ARQUIVAMENTO & INABILIT AÇÃO & MULTA & PROIBIÇÃO PARA ATUAR & Total \\
\hline Auditores Independentes & 0 & 0 & 0 & 1 & 1 & 2 \\
\hline Bancos - Comercial / Múltiplo & 0 & 2 & 8 & 38 & 0 & 48 \\
\hline Bancos de Investimento / Desenvolvimento & 0 & 2 & 1 & 1 & 0 & 4 \\
\hline Caixas & 3 & 0 & 1 & 11 & 0 & 15 \\
\hline Consórcios & 0 & 1 & 7 & 17 & 0 & 25 \\
\hline Cooperativas & 9 & 21 & 100 & 35 & 0 & 165 \\
\hline Corretoras & 0 & 5 & 15 & 42 & 0 & 62 \\
\hline Distribuidoras & 0 & 0 & 1 & 2 & 0 & 3 \\
\hline Financeiras & 0 & 0 & 12 & 1 & 0 & 13 \\
\hline Mercado Marginal - Lei 4.595 & 0 & 1 & 0 & 1 & 0 & 2 \\
\hline Pessoa Jurídica Não Financeira & 0 & 19 & 0 & 130 & 0 & 149 \\
\hline Pessoas Físicas & 0 & 20 & 2 & 785 & 0 & 807 \\
\hline Sociedade de Crédito ao Microempreendedor & 0 & 0 & 0 & 2 & 0 & 2 \\
\hline \multicolumn{7}{|l|}{ Ilícitos cambiais } \\
\hline Corretoras & 0 & 0 & 4 & 1 & 0 & 5 \\
\hline Pessoa Jurídica Não Financeira & 0 & 0 & 1 & 61 & 0 & 62 \\
\hline Pessoas Físicas & 0 & 0 & 0 & 1 & 0 & 1 \\
\hline Total & 12 & 71 & 152 & 1129 & 1 & 1365 \\
\hline
\end{tabular}

Fonte: Bacen, 2018. 
Tabela 9 - Penalidades aplicadas no ano de 2016

\begin{tabular}{|c|c|c|c|c|c|}
\hline \multicolumn{6}{|c|}{ Penalidades aplicadas no ano de 2016} \\
\hline Tipo de instituição & ADVERTÊNCIA & ARQUIVAMENTO & INABILIT AÇÃO & MULTA & Total \\
\hline Arrendamento Mercantil & 0 & 0 & 0 & 2 & 2 \\
\hline Bancos - Comercial / Múltiplo & 0 & 1 & 10 & 14 & 25 \\
\hline Bancos de Investimento / Desenvolvimento & 0 & 0 & 10 & 1 & 11 \\
\hline Consórcios & 0 & 2 & 3 & 11 & 16 \\
\hline Cooperativas & 19 & 15 & 112 & 53 & 199 \\
\hline Corretoras & 2 & 0 & 18 & 17 & 37 \\
\hline Distribuidoras & 0 & 1 & 1 & 3 & \\
\hline Financeiras & 0 & 0 & 4 & 15 & 19 \\
\hline Mercado Marginal - Lei 4.595 & 0 & 25 & 0 & 22 & 47 \\
\hline Pessoa Jurídica Não Financeira & 0 & 4 & 0 & 71 & 75 \\
\hline Pessoas Físicas & 0 & 4 & 2 & 1016 & 1022 \\
\hline Sociedade de Crédito ao Microempreendedor & 0 & 0 & 0 & 5 & \\
\hline \multicolumn{6}{|l|}{ Ilícitos cambiais } \\
\hline Pessoa Jurídica Não Financeira & 0 & 1 & 0 & 2 & \\
\hline Total & 21 & 53 & 160 & 1232 & 1466 \\
\hline
\end{tabular}

Fonte: Bacen, 2018.

Tabela 10 - Penalidades aplicadas no ano de 2017

\begin{tabular}{|c|c|c|c|c|c|}
\hline \multicolumn{6}{|c|}{ Penalidades aplicadas no ano de 2017} \\
\hline Tipo de instituição & ADVERTÊNCIA & ARQUTVAMENTO & INABILIT AÇÃO & MULTA & Total \\
\hline Bancos - Comercial / Múltiplo & 0 & 0 & 0 & 22 & 22 \\
\hline Consórcios & 0 & 0 & 0 & 2 & 2 \\
\hline Cooperativas & 4 & 1 & 5 & 3 & 13 \\
\hline Pessoa Jurídica Não Financeira & 0 & 5 & 0 & 236 & 241 \\
\hline Pessoas Físicas & 0 & 14 & 0 & 2101 & 2115 \\
\hline Ilícitos cambiais & & & & & \\
\hline Total & 4 & 20 & 5 & 2364 & 2393 \\
\hline
\end{tabular}

Fonte: Bacen, 2018.

\section{ANEXO II - VALOR DAS MULTAS APLICADAS POR ANO (2008 A 2017) EM TERMOS REAIS PARA CADA INSTITUIÇÃO}

Tabela 1 - Valor das multas aplicadas em termos reais (2008 a 2012) - Base em 2008

\begin{tabular}{|c|c|c|c|c|c|}
\hline \multicolumn{6}{|c|}{ VALOR DAS MULTAS APLICADAS EM TERMOS REAIS (2008 - 2012) - BASE EM 2008} \\
\hline TIPO DE INSTITUIÇÃO & 2008 & 2009 & 2010 & 2011 & 2012 \\
\hline ARRENDAMENTO MERCANTIL & $\mathrm{X}$ & $\mathrm{X}$ & $\mathrm{X}$ & $\mathrm{X}$ & \\
\hline AUDITORES INDEPENDENTES & $950.000,00$ & $23.967,02$ & $\mathrm{x}$ & $84.993,85$ & $521.976,56$ \\
\hline BANCOS - COMERCIAL/MÚLTIPLOS & $4.425 .946,84$ & $479.340,43$ & $1.760 .583,76$ & $1.551 .980,84$ & $10.028 .226,77$ \\
\hline BANCOS DE INVESTIMENTO/DESENVOLVIMENTO & $125.000,00$ & $191.736,17$ & $90.518,45$ & $x$ & $698.645,55$ \\
\hline CAIXAS & $\mathrm{x}$ & $\mathrm{x}$ & $\mathrm{x}$ & $\mathrm{x}$ & \\
\hline CONSÓRCIOS & $214.456,21$ & $275.879,99$ & $342.625,53$ & $789.291,20$ & $874.527,90$ \\
\hline COOPERATIVAS & $1.141 .121,37$ & $95.985,08$ & $315.319,47$ & $298.096,84$ & $193.532,85$ \\
\hline CORRETORAS & $100.000,00$ & $96.395,36$ & $113.148,06$ & $79.554,24$ & $855.143,69$ \\
\hline CRÉDITO IMOBILIÁRIO & $50.000,00$ & $\mathrm{x}$ & $x$ & $594.956,92$ & \\
\hline DISTRIBUIDORAS & $202.252,53$ & $210.909,79$ & $234.850,11$ & $183.648,61$ & $818.941,08$ \\
\hline FINANCEIRAS & $x$ & $x$ & $90.518,45$ & $224.141,70$ & $562.920,16$ \\
\hline MERCADO MARGINAL (CONSÓRCIOS) & $100.000,00$ & $132.250,02$ & $316.814,56$ & $x$ & $280.261,26$ \\
\hline MERCADO MARGINAL & $x$ & $x$ & $452.592,23$ & $\mathrm{x}$ & $401.520,43$ \\
\hline PESSOA JURÍDICA NÃO FINANCEIRA & $90.028 .844,80$ & $45.066 .641,42$ & $8.322 .202,05$ & $301.248,12$ & $631.177,51$ \\
\hline PESSOAS FÍSICAS & $113.789,83$ & $306.390,75$ & $692.983,26$ & $790.772,22$ & $1.006 .523,34$ \\
\hline SOCIEDADES DE CRÉDITO AO MICROEM & $x$ & $\mathrm{x}$ & $x$ & $\mathrm{x}$ & \\
\hline \multicolumn{6}{|l|}{ ILÍCITOS CAMBIAIS } \\
\hline BANCOS - COMERCIAL/MÚLTIPLOS & $220.000,00$ & $x$ & $\mathrm{x}$ & $\mathrm{x}$ & \\
\hline CORRETORAS & $x$ & $x$ & $x$ & $\mathrm{x}$ & \\
\hline PESSOA JURÍDICA NÃO FINANCEIRA & $261.753 .417,20$ & $258.175 .045,47$ & $18.141 .133,93$ & $16.306 .365,74$ & $3.201,72$ \\
\hline PESSOAS FÍSICAS & $142.173,59$ & $15.235,81$ & $\mathrm{X}$ & $\mathrm{x}$ & $40.152,04$ \\
\hline TOTAL & $359.567 .002,37$ & $305.069 .777,31$ & $30.873 .289,84$ & $21.205 .050,28$ & $16.916 .750,86$ \\
\hline
\end{tabular}

Fonte: Bacen, 2018. Elaboração Própria. 
Tabela 2 - Valor das multas aplicadas em termos reais (2013 a 2017) - Base em 2008

\begin{tabular}{|c|c|c|c|c|c|}
\hline \multicolumn{6}{|c|}{ VALOR DAS MULTAS APLICADAS EM TERMOS REAIS (2013 - 2017) - BASE EM 2008} \\
\hline TIPO DE INSTITUIÇÃO & 2013 & 2014 & 2015 & 2016 & 2017 \\
\hline ARRENDAMENTO MERCANTIL & $\mathrm{X}$ & $\mathrm{X}$ & $\mathrm{X}$ & $121.150,70$ & $\mathrm{X}$ \\
\hline AUDITORES INDEPENDENTES & $379.114,75$ & $1.075 .957,66$ & $321.927,69$ & $\mathrm{X}$ & $\mathrm{X}$ \\
\hline BANCOS - COMERCIAL/MÚLTIPLOS & $5.535 .075,38$ & $758.514,53$ & $1.666 .303,92$ & $45.247 .583,11$ & $1.243 .600,36$ \\
\hline BANCOS DE INVESTIMENTO/DESENVOLVIMENTO & $170.601,64$ & $\mathrm{x}$ & $64.385,54$ & $60.575,35$ & $\mathrm{X}$ \\
\hline CAIXAS & $\mathrm{x}$ & $x$ & $708.240,91$ & $\mathrm{X}$ & $\mathrm{X}$ \\
\hline CONSÓRCIOS & $1.122 .126,54$ & $1.145 .128,50$ & $1.354 .534,72$ & $1.176 .321,76$ & $24.485,47$ \\
\hline COOPERATIVAS & $233.534,69$ & $2.768 .275,18$ & $1.523 .057,94$ & $1.393 .233,01$ & $71.784,29$ \\
\hline CORRETORAS & $17.094 .438,76$ & $70.166 .123,65$ & $365.576 .231,02$ & $18.004 .900,96$ & $x$ \\
\hline CRÉDITO IMOBILIÁRIO & $227.468,85$ & $x$ & $x$ & $\mathrm{X}$ & $\mathrm{X}$ \\
\hline DISTRIBUIDORAS & $x$ & $78.381,02$ & $786.830,23$ & $17.095 .560,58$ & $\mathrm{x}$ \\
\hline FINANCEIRAS & $1.213 .167,21$ & $\mathrm{x}$ & $64.385,54$ & $1.105 .500,11$ & $\mathrm{x}$ \\
\hline MERCADO MARGINAL (CONSÓRCIOS) & $\mathrm{x}$ & $x$ & $x$ & $\mathrm{x}$ & $\mathrm{X}$ \\
\hline MERCADO MARGINAL & $379.114,75$ & $356.277,37$ & $160.963,84$ & $30.545 .139,00$ & $\mathrm{X}$ \\
\hline PESSOA JURÍDICA NÃO FINANCEIRA & $1.660 .822,78$ & $1.204 .986,93$ & $939.735,65$ & $685.764,36$ & $1.580 .598,46$ \\
\hline PESSOAS FÍSICAS & $1.384 .671,34$ & $1.687 .034,87$ & $2.732 .681,02$ & $4.389 .177,58$ & $7.514 .639,70$ \\
\hline SOCIEDADES DE CRÉDITO AO MICROEMPREENDEDOR & $x$ & $71.255,47$ & $28.973,49$ & $118.121,93$ & $\mathrm{X}$ \\
\hline \multicolumn{6}{|l|}{ ILÍCITOS CAMBIAIS } \\
\hline BANCOS - COMERCIAL/MÚLTIPLOS & $\mathrm{X}$ & $\mathrm{X}$ & $\mathrm{X}$ & $\mathrm{X}$ & $\mathrm{X}$ \\
\hline CORRETORAS & $596.033,48$ & $142.510,95$ & $48.289,15$ & $\mathrm{X}$ & $\mathrm{X}$ \\
\hline PESSOA JURÍDICA NÃO FINANCEIRA & $21.635 .341,24$ & $47.109 .525,51$ & $100.829 .494,92$ & $867.456,56$ & $\mathrm{X}$ \\
\hline PESSOAS FÍSICAS & $8.318 .030,68$ & $15.592 .263,10$ & $51.582,59$ & $\mathrm{X}$ & $\mathrm{X}$ \\
\hline TOTAL & $59.949 .542,08$ & $142.156 .234,76$ & $476.857 .618,17$ & $120.810 .484,99$ & $10.435 .108,28$ \\
\hline
\end{tabular}

Fonte: Bacen, 2018. Elaboração Própria. 